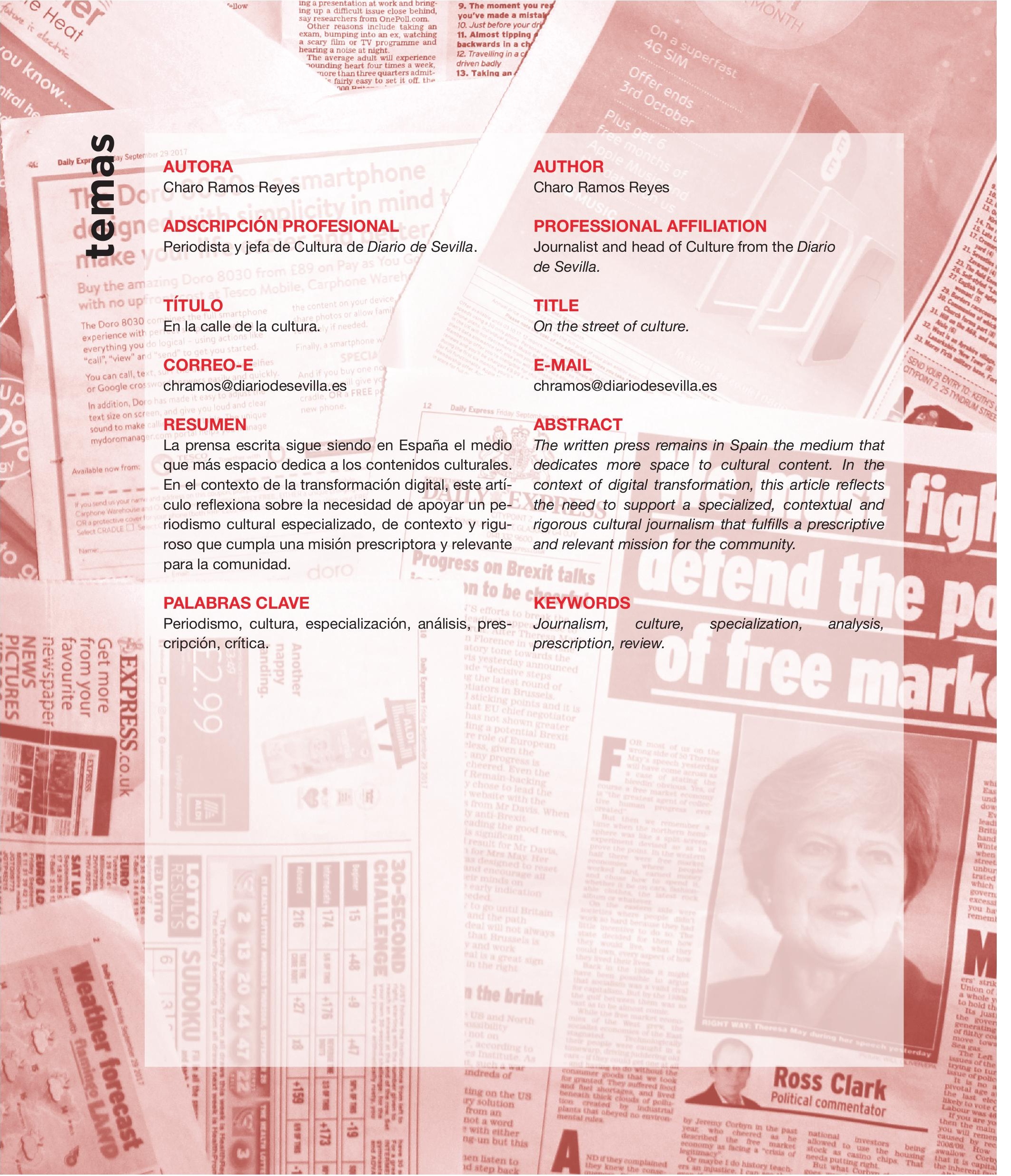




\section{En la calle de la cultura}

\section{Charo Ramos Reyes}

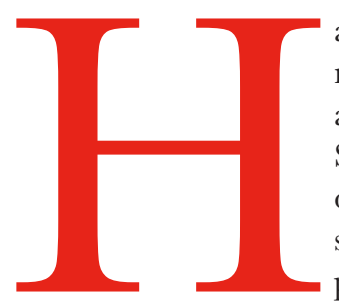

ace ahora veinte años, el escritor Ignacio Martínez de Pisón acudió al aula cultural de El Corte Inglés de Sevilla, cuyas actividades coordinaba otro certero narrador, Fernando Iwasaki, y al acabar el encuentro con la ció a su anfitrión el que la charla hubiera discurrido en unos términos que juzgó intelectualmente provechosos y amables. «Estos periodistas culturales están entre los mejores de España, se han leído todos mis libros». Fue probablemente la primera vez que reflexioné sobre mi pertenencia a un colectivo en el que siempre había soñado militar pero que siempre asocié a la generación anterior a la mía.

Efectivamente, nos leíamos los libros antes de entrevistar al autor. Y no solo el título que lo traía de promoción a la capital andaluza, sino todos los anteriores, y con especial atención aquellos que habían marcado un punto de inflexión en su trayectoria, como ocurriría en su caso con la no ficción Enterrar a los muertos o con Las armas y las letras en el caso de Andrés Trapiello, libros que nos ayudarían a redescubrir nuestra historia literaria y política arrojando luz sobre figuras opacadas por prejuicios y banderías. Creo que todos los periodistas culturales que conozco, de alguna manera, quieren contribuir a una hazaña así: hacer justicia a un creador, devolver la vida a un texto que parecía irrelevante al juicio crítico años atrás, acercar a un lector una obra de arte sin cuya textura y emoción la vida valdría algo menos la pena.

«Leer es revolucionario», defendía el editor italiano Carlo Feltrinelli referido a un mundo en que las personas que están bajo el poderoso influjo de las redes sociales dedican cada vez menos tiempo a sí mismas. Recuerda la cita Jorge Herralde, fundador de Anagrama, en su libro Un día en la vida de un editor, donde abunda en la idea de que «en un momento en el que todo el mundo está enganchado veinticuatro horas al día a la pantalla el libro es el instrumento más sofisticado para la profundidad intelectual».

Aspirar a la profundidad y al rigor, al análisis, en suma, a un periodismo reposado y de segunda velocidad, más que a la acumulación informativa sin filtro ni jerarquía, es la misión del periodista cultural, cuyo trabajo debería ser también prescriptor y relevante, cultural y políticamente, para la sociedad en la que trabaja.

Nuestro oficio está en plena mutación por la crisis financiera y sobre todo por la transformación digital, que no solo ha afectado a los hábitos de los lectores sino al propio 
modelo de negocio de los medios de comunicación, que buscan cómo financiar sus proyectos ante la caída de los ingresos publicitarios. Suscriptores o muros de pago pueden ser el futuro del periodismo, como parecen demostrar los ejemplos de empresas que han conseguido sanear sus cuentas a la manera de The Washington Post o The New York Times, pero de momento nadie ha dicho la última palabra.

Entiendo el periodismo cultural como una disciplina en el sentido que le otorga uno de sus maestros, Sergio Vila-Sanjuán: como una pasión por la creación y las actividades culturales, que son el objeto de nuestro trabajo. Y siguiendo la definición que el periodista barcelonés y director del suplemento Gultural de La Vanguardia incluye en su excelente libro Una crónica del periodismo cultural, lo que nos diferencia respecto al columnismo, la crítica o el ensayo es «el acceso directo a las fuentes y el conocimiento también directo y personal de los lugares que se describen: la capacidad de generar documentos vivos».

El periodismo cultural es un oficio, como el periodismo a secas, pero como recuerda Vila-Sanjuán la consolidación de la industria cultural española a raíz de la democracia y la expansión internacional del ocio cultural provocaron que en los últimos cuarenta años comenzara a haber en numerosos medios secciones autónomas de cultura. Incluso diarios de tirada nacional dotaron a sus ediciones regionales de especialistas en el tema. El periódico para el que trabajo, Diario de Sevilla, también nació en 1999 garantizando su compromiso con el periodismo cultural y contratando para ello a un sólido equipo de críticos y lanzando un suplemento semanal, Culturas, que ofreció una ambiciosa mirada desde Andalucía sobre las actividades culturales. No fue una operación en tierra extraña ya que la cabecera matriz de la empresa, Diario de Cádiz, había contado durante años con una de las mejores secciones de cultura de la prensa española, comandada por Lalia González-Santiago, otra figura recurrente al hablar de cultura y medios de comunicación en Andalucía.

Pese a que el consumo cultural está creciendo en nuestro país y en 2019 los españoles escuchan música, leen y van al cine más que hace cuatro años, según la Encuesta de Hábitos y Prácticas Culturales en España (2018-2019) que elabora el Ministerio de Cultura, la difusión de las actividades culturales ha visto rebajar sus espacios tradicionales a raíz de la crisis económica. También la eclosión de internet, con sus blogs y revistas digitales especializadas, ha obligado a replantear el escenario en que trabajamos, en muchos casos a una economía de subsistencia.
Entiendo el periodismo

cultural como una disciplina

en el sentido que le otorga

uno de sus maestros,

Sergio Vila-Sanjuán: como

una pasión por la creación

y las actividades culturales,

que son el objeto

de nuestro trabajo.

La situación no ha sido, por desgracia, muy diferente en los medios públicos y en este momento solo subsiste un espacio televisivo dedicado a los libros en España, Página Dos que dirige y presenta Oscar López en RTVE, y la presencia del arte de vanguardia mantiene una presencia ínfima comparada con las apuestas por recortar la distancia con los países del entorno que asumieron en la transición de espacios como Metrópolis, referente desde 1985 en su género y considerado el programa cultural más longevo de la televisión en España.

Descubrir a creadores que trabajan en la periferia de la cultura de masas ha sido siempre uno de los alicientes del periodismo cultural. Todavía recuerdo mi primera entrevista para Diario de Cádiz cuando aún era estudiante y González-Santiago me encargó entrevistar al artista campogibraltareño Chema Cobo, que exhibía su enigmática serie de los Joker. Me impresionó su mundo inclasificable y personal, su colorido de aliento pop, su habilidad para el dibujo, el relato de sus obsesiones estéticas. Cuando llegué a la redacción y lo planteé, eufórica, mi jefa me dijo sin alzar la vista: «No te dejes impresionar demasiado». Y ese consejo tan breve ha sido acaso uno de los más valiosos en mis casi treinta años de ejercicio profesional, y sin que ello suponga un demérito para Chema Cobo, uno de los mejores artistas españoles de su generación. 
Un periodista cultural no debería masajear el ego de sus entrevistados, ni adular los intereses de la industria cultural, tan rearmada durante los años noventa y siguientes gracias, en nuestro contexto, al apoyo de las políticas autonómicas. Debe, por el contrario, ofrecer un relato que interpele, que muestre las contradicciones de los procesos creativos, mediante el ejercicio de un periodismo reposado, desgajado del frenesí de las agendas y declaraciones, que ilumine los claroscuros y pliegues por donde avanza la creación. En este año, por ejemplo, ha sido muy interesante atender al despegue de la literatura punki y deslenguada de Cristina Morales gracias al respaldo de su Premio Herralde a Lectura fácil. Emociona además que esto suceda en el cincuenta aniversario de la editorial Anagrama, un sello donde en los últimos años han encontrado su casa autores andaluces que antes habíamos acompañado desde sellos más minoritarios, como la citada Morales, Sara Mesa o Marina Perezagua.

Aplaudir lo sancionado por el mercado, hacernos eco del gusto imperante, es uno de los riesgos del periodismo cultural en un momento en que la información suele convertirse en mercancía de cambio al servicio de los poderes que financian los medios de comunicación, ya sean económicos o políticos, por citar los más recurrentes. Elegir es excluir y configurar una marca, permanecer fiel a ella. Que la marca sea creíble y pertinente durante años son retos del periodismo cultural, ahora y hace cuarenta años.

En los medios generalistas y especialmente en el sector privado las secciones han ido reduciéndose de capital humano desde el inicio de la crisis y esto ha supuesto un freno para la especialización cultural. Como consecuencia, hay una gran dependencia de la agenda institucional y poco tiempo para desarrollar agendas propias así como para el análisis y la reflexión, que consumen mayores esfuerzos y recursos.

Del mismo modo que la concentración en grandes grupos editoriales conlleva la sobreexposición mediática de sus libros y productos, y puede impedir ver los brotes verdes de los sellos minoritarios e independientes, las exposiciones patrocinadas por las fundaciones de las cajas de ahorro y bancos tienen un hueco asegurado en las agendas y en la cobertura de las secciones de cultura. Les presuponemos calidad pero, si no fuera así, difícilmente en las condiciones actuales podríamos obviarlas dado que suelen estar promovidas por anunciantes fieles.

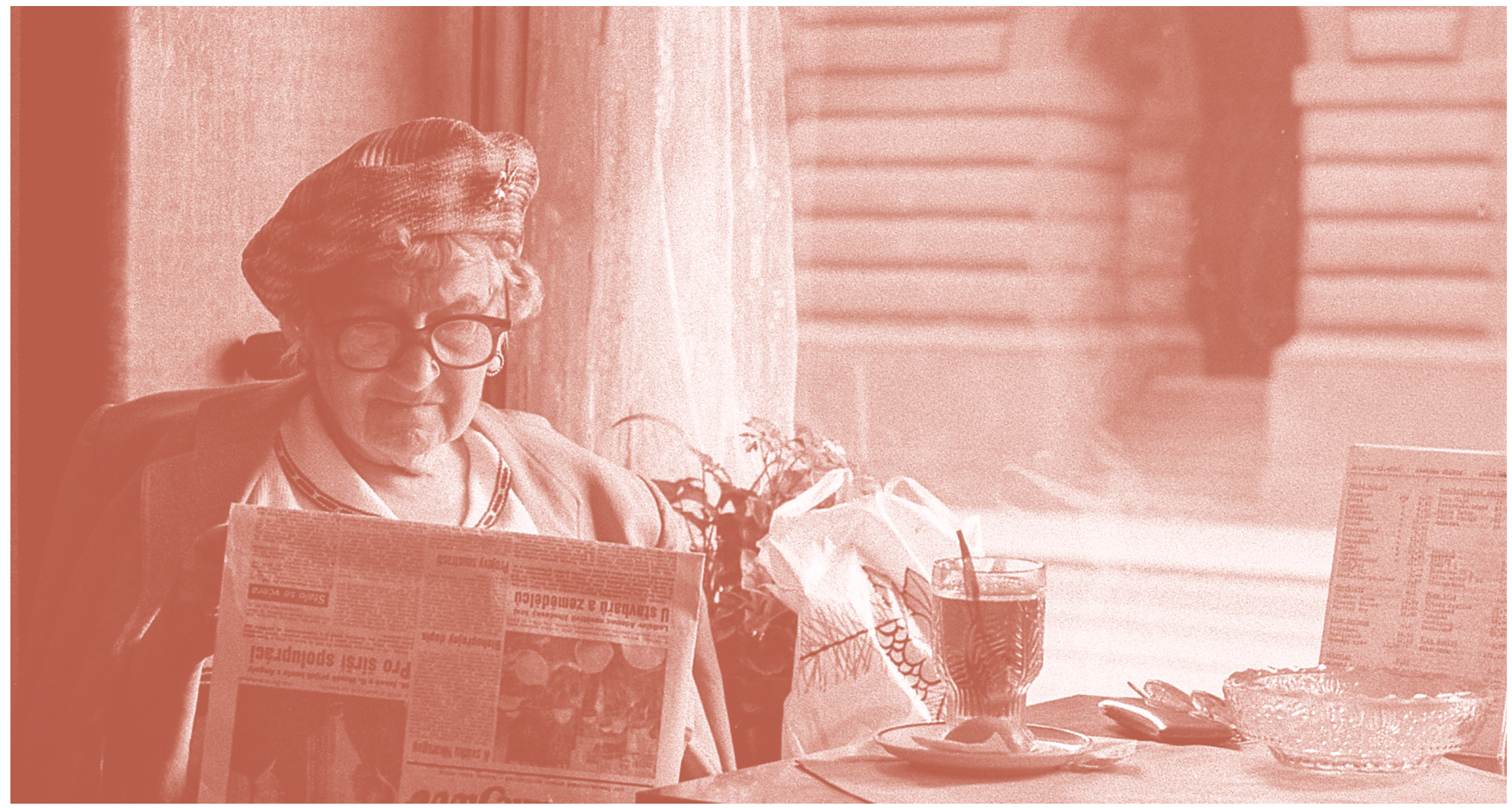


Confiamos por ello a los críticos el ejercicio responsable de una crítica libre y sin cortapisas, ajena a las dinámicas que sostienen las relaciones entre las fuentes y los periodistas culturales, que en este momento son más conciliadoras que beligerantes. La falta de personal en las secciones y por tanto de tiempo para atender los contenidos desde diversas perspectivas han favorecido que la entrevista sea el género recurrente en estos tiempos y abunden, por supuesto, las que se realizan a creadores en gira de promoción de su libro o su obra.

La calidad de una sección de cultura depende de sus redactores tanto como de su equipo de críticos, que no solo aportan un juicio independiente y relevante, sino que proveen a la plantilla de pistas e informaciones que son especialmente útiles cuando tienen que elaborar reportajes, preparar entrevistas o escribir obituarios, ese género que no ha perdido relevancia en estos tiempos de bulimia digital sino todo lo contrario. Tal vez por la percepción de lo frágil que son la memoria y los archivos en los tiempos de internet y el big data, honrar a los muertos es una práctica ante la cual los editores no escatiman páginas ni recursos económicos.

En la actualidad, según los datos referidos a 2017 del último informe publicado por la Fundación Contemporánea, elaborado por Kantar Media, la prensa escrita es el medio que más importancia da a la cultura y la principal fuente en audiencia, comparada con la radio y la televisión. Las cadenas generalistas de televisión, pese a ser el medio que más audiencia atrae, apenas le dan cobertura. Los medios regionales, y esto es llamativo, dedican más espacio al ámbito cultural que sus homólogos de difusión nacional.

Entre el 1 de enero y el 31 de diciembre de 2017, El Mundo fue el periódico que más noticias de Cultura publicó, y fueron 12.912. Diario de Sevilla aparece en el noveno puesto en este ranking nacional con 5.812 noticias culturales, muy cerca del Ideal de Granada, que publicó 6.008. El impacto en la audiencia no fue equivalente pues el medio más leído en cultura fue El País, que había sido el quinto en número de publicaciones. Las áreas más atendidas fueron el cine en primer lugar seguido por la literatura y la música.

Sin embargo, el desplazamiento de internet como fuente ha cambiado radicalmente el escenario y, como constata el informe de la Fundación Contemporánea, los medios generalistas reducen porcentualmente la presencia de noticias culturales en sus ediciones digitales pese a incluir más secciones (como gastronomía, sucesos, moda, lujo o plataformas) que en sus ediciones impresas.
En ese contexto los blogs culturales y revistas especializadas han florecido en esta primavera digital y esto es especialmente beneficioso para ciertas áreas, como la danza, las artes plásticas, la arquitectura, el cómic, el diseño o la filosofía, menos atendidas en las secciones de los medios generalistas.

Durante más de veinte años me he dedicado al periodismo cultural en medios provinciales y regionales, siempre impresos. Fundamentalmente escribo del mercado del arte, de galerías y museos, de exposiciones. También de literatura. El periodismo cultural exige un amplio bagaje intelectual pero sobre todo requiere de la curiosidad necesaria para aceptar someterte a un examen continuo y diario, a una formación adulta constante. Joseph Campbell, el celebrado autor de Las máscaras de Dios, lo expresó con gracia. Para él, «el periodista tiene la obligación de educarse a sí mismo en público».

Una de las ventajas del periodismo de provincias es la posibilidad que brinda de tomar el pulso a la escena cultural cercana. Atender las manifestaciones que despuntan, que son más interesantes o novedosas, que tienen ambición y podrían trascender el marco local.

La evolución de la danza flamenca en Andalucía ofrece un buen ejemplo de cómo el periodismo cultural puede acompañar el cambio social y a la vez anticiparlo o favorecerlo. Desde que el bailaor sevillano Israel Galván debutó en 1998 con su propia compañía en la X Bienal de Flamenco con ¡Mira!/ Los zapatos rojos la prensa ha formado parte de su conversación con el público, ha ayudado a entender el contexto y los mecanismos de trabajo de un creador tan inclasificable como enraizado en una tradición muy concreta. Las controversias sobre su arte, que nunca le han abandonado del todo, han generado a lo largo de los años pintorescas páginas en la prensa más ensimismada. Pero son mayoría las voces que han alentado y han sido testigos de la maduración de su vocabulario coreográfico, hoy internacionalmente respetado y programado, y en esa dialéctica el periodismo cultural y la crítica de baile se han visto fortalecidos.

El periodismo cultural es, en suma, una puerta excelente para acceder a los valores que nos identifican como comunidad, como colectivo o como ciudad. Y concluyo pensando en Manuel Chaves Nogales, probablemente el mejor periodista español de la primera mitad del siglo XX y uno de los que ha modelado nuestra mirada de periodistas culturales a lo largo de los últimos treinta años.

Aunque poca gente lo recuerda así, ya que se dio a conocer internacionalmente como reportero de guerra y 
cronista político, antes de dirigir el periódico fiel a Azaña Ahora, Manuel Chaves Nogales era también un gran periodista cultural, como demuestra la variedad de sus lecturas, su interés por las actividades teatrales, musicales y operísticas, su atención a la arquitectura y las bellas artes, y sobre todo su respeto por el patrimonio histórico. Estas constantes se aprecian en sus grandes libros de reportajes, como Lo que ha quedado del imperio de los zares, donde entrevista en París a una joven Irène Némirovsky con motivo de la publicación de su primera novela. Pero la pasión por la cultura late en sus crónicas, entrevistas y artículos, recogidos en los volúmenes de su obra periodística que editó la Diputación de Sevilla. Y en su obra de juventud La ciudad, un retrato de esa Sevilla escindida entre la tradición y el pulso de la modernidad que aún sorprende por su vigencia.

Creo que el haber acompañado la recuperación de una obra de la calidad de la de Chaves a lo largo de los años, mediante reportajes, entrevistas y reseñas, y el poder difundirla dentro y fuera de España resume la misión que atribuyo al periodismo cultural: dar testimonio de los mejores logros creativos de una sociedad alentando su lectura, su visión o su disfrute. Ser la brújula que marque la excelencia. 